\title{
Enhancing research collaborations: Three key management challenges
}

\author{
Gabriele Bammer ${ }^{\mathrm{a}, \mathrm{b}, *}$ \\ a National Centre for Epidemiology and Population Health, ANU College of Medicine and Health Sciences, \\ The Australian National University, Canberra ACT 0200, Australia \\ b Hauser Center for Nonprofit Organizations, Harvard University, 79 John F. Kennedy Street, \\ BT-232, Cambridge, MA 02138, USA
}

\section{A R T I C L E I N F O}

\section{Article history:}

Received 25 September 2006

Received in revised form 17 August 2007

Accepted 18 March 2008

Available online 28 April 2008

\section{Keywords:}

Collaboration

Integration

Boundary

Authorization

Evaluation

\begin{abstract}
A B S T R A C T
This conceptual paper explores three areas of research collaboration: (a) effectively harnessing differences, (b) setting defensible boundaries and (c) gaining legitimate authorization. The focus is on their potential lessons for individuals leading and managing research collaborations, evaluation of research partnerships and areas for further investigation. Examples from three partnerships - building the atomic bomb, the Human Genome Project and the World Commission on Dams - are used to highlight key elements of the ideas presented. The paper provides a framework for systematically thinking about integration of different perspectives and other elements essential to any particular collaboration. It also sketches out ideas for (1) managing differences which may destroy partnerships, (2) deciding what the collaboration should encompass, (3) understanding and accommodating forces which may distort what the collaboration is able to achieve, and (4) enlisting necessary supporters while preserving research independence.
\end{abstract}

(c) 2008 Elsevier B.V. All rights reserved.

\section{Introduction}

For research to contribute to addressing major social, environmental and technical problems, collaborations across disciplines and between researchers and practitioners (including government policy makers, business leaders, and community advocates) are increasingly being seen as essential. Significant policy attention has been paid to funding such interdisciplinary and transdisciplinary collaborations. For example, the European Union aims to promote cross-national, cross-disciplinary and cross-sectoral collaborations through its seventh Framework Programme for Research and Technological Development (http://ec. europa.eu/research/fp7/pdf/fp7-inbrief_en.pdf). Interdis-

\footnotetext{
* Correspondence address: National Centre for Epidemiology and Population Health, ANU College of Medicine and Health Sciences, The Australian National University, Canberra ACT 0200, Australia. Tel.: +61 26125 0716; fax: +61 261250740 .

E-mail address: Gabriele.Bammer@anu.edu.au.
}

ciplinary and transdisciplinary collaborations are also fostered by funding arrangements such as the Australian Research Council Research Networks (www.arc.gov.au/ ncgp/networks/networks_default.htm) which target national priorities and the US Transdisciplinary Tobacco Use Research Centers (www.tturcpartners.com), which focus on one specific area. There are also specific funding programs to enhance industry-science partnerships, such as Australian Cooperative Research Centres (https://www.crc.gov.au/Information/default.aspx) and the US National Science Foundation funded Engineering Research Centres (www.erc-assoc.org).

To complement these policy initiatives there is a growing body of research on collaborations. In this journal alone, papers have covered a range of areas, such as examinations of the increase in collaborations and team sizes (Adams et al., 2005), patterns of collaboration networks (Wagner and Leydesdorff, 2005), motives, choices and strategies for collaboration, (Bozeman and Corley, 2004; Katz and Martin, 1997; Landry and Amara, 1998; Lee, 1996; Melin, 2000), the measurement of collaboration (Katz and Martin, 1997), 
how collaborations are organized (Chompalov et al., 2002; Corley et al., 2006; Hackett et al., 2004) and collaboration success (Corley et al., 2006; Porac et al., 2004; Rigby and Edler, 2005).

Nevertheless there are some key practical issues about research collaborations which seem to have received little attention, so that investigators funded to lead partnerships are often left to learn by trial and error, making success a hit-or-miss affair. This paper starts by focusing on a primary challenge of research collaborations, namely effectively harnessing differences, and provides a framework for integrating the core elements relevant to the collaboration. It then sketches out a range of ideas flowing from that starting point. It first covers differences which may impede partnerships, and then branches out to two related areas-setting defensible boundaries and gaining legitimate authorization.

Although the primary target audience is individual researchers who are collaboration leaders and managers, the three strands of ideas covered in the main sections of the paper - harnessing differences, setting defensible boundaries and gaining legitimate authorization - are brought together in the fourth section to reflect on their implications for the evaluation of research collaborations, both in terms of the focus of evaluation and the processes for conducting it. The paper also sets out to stimulate research on these practical issues and concludes with some key areas for further investigation.

As outlined above, the starting point is effective harnessing of differences. Collaborations occur for a range of reasons. For example, Bozeman and Corley (2004) and Katz and Martin (1997) summarize substantial literature on this, citing reasons which include: access to expertise or particular skills, access to equipment or resources, crossfertilization across disciplines, improved access to funding, learning tacit knowledge about a technique, obtaining prestige, visibility or recognition, and enhancing student education. I suggest that most of these reasons can be boiled down to one overarching consideration, namely that the point of working with someone else is that they have a perspective, skills, resources or some other attribute that contributes something relevant to addressing the research problem, either in improving understanding about it or in implementing that understanding in decisions and action. In other words, collaborations generally aim to draw together partners with diverse relevant attributes. If we look at collaborations through the lens of harnessing differences, it quickly becomes evident that the distinctions between research partners cannot be confined to those which progress understanding of or effective action on the problem. Variations in ideas, interests and personality will also provide potential sources of unproductive conflict. I propose that a critical element of collaboration is to recognise that differences between research partners fall into these two categories. One involves the differences that are key to and underpin the partnership, which must be effectively harnessed. The second is the differences that are incidental to the collaboration and that may undermine the achievement of its goals. These differences must be effectively managed. Understanding and dealing with these two types of differences is important when researchers want to work together, but even more so when collaboration is motivated by funding rather than the desire of the researchers. Such collaborations of convenience to meet the requirements of funders are now common. The first section of this paper presents a framework for integrating relevant differences and lays out ideas for how the differences that may be seen as incidental to the partnership can be managed.

The second section moves on to a related issue, namely which relevant differences to include in a research collaboration. The challenging problems that societies currently face involve a complex web of interconnections. For example, tackling an environmental issue like human-induced global climate change involves altering industrial, agricultural and personal practices, which are intertwined. Relevant considerations include economic growth and prosperity, employment, energy supplies, food security, transport, and population growth. It is impossible for any one research project or even program to consider everything that may possibly be relevant. Such a systembased view highlights the importance of boundary setting, in other words determining what will be included and excluded in any particular research collaboration. The second section of this paper covers ideas about how defensible boundaries can be set. This involves matching boundaries and the objectives of the research, while coping with inevitable restrictions in funding, personnel and other resources.

Consideration of research collaboration boundaries, in turn, may raise questions of legitimacy and authorization and these are tackled in the third section of the paper. First, the objectives and research design need support from funders, peer-reviewers and participating stakeholders. Second, research which addresses complex problems and which aims to involve researchers from many disciplines, as well as various stakeholders often requires a range of inter-institutional agreements about use of data, funding allocations, responsibility for outputs, publication rights and so on. Three key challenges here are to determine what sort of authorization is essential, to minimise transaction costs and to minimise the loss of research independence. This paper explores the first and last of these, namely ideas about gaining legitimate authorization, while minimising the loss of research independence.

As outlined earlier, these ideas are then used to reflect on the evaluation of research collaborations, both in terms of the focus of evaluation and the processes for conducting it. In addition, the ideas presented show there are many areas where the collation of evidence and new empirical studies are warranted and the conclusion focuses on a number of key research areas this paper aims to stimulate.

Three case studies are used as illustrations. They are: building the atomic bomb (1941-1945), the Human Genome Project (1986-2001) and the World Commission on Dams (1998-2000). They were selected as examples of very large-scale collaborations which illustrate three different types of partnerships: (1) involving only researchers, (2) involving researchers and powerful practitioners and (3) bringing researchers together with practitioners from opposite ends of the power spectrum. While these do not illustrate the full gamut of types of research collaborations 
that now exist, they do tease out one important dimension of research collaborations, namely whether they are largely based in the academy or if they also engage with stakeholders. The focus here is on engagement with politically and economically powerful stakeholders, and whether or not this is balanced by the inclusion of powerless stakeholders who are affected by, but generally have little ability to influence, the decisions made. ${ }^{1}$

The Human Genome Project involved only researchers, although as the project progressed competition from, rather than partnership with, one company became important. The atomic bomb project involved researchers and powerful practitioners, particularly the military and private industry. Researchers at the World Commission on Dams worked with powerful business and funding interests, such as proponents of companies building dams and the World Bank, as well as representatives of those with little power, such as people displaced by dams. While individuals adversely affected by dams lack power on their own, they had become a force to be reckoned with through collective action.

\section{Effective harnessing of differences}

As outlined above, research collaborations can be usefully viewed as bringing a range of perspectives and skills to bear on the issue of interest. However the differences between partners cannot be limited to those which progress the partnership. Differences in world-views, motivations and ways of doing things will also provide potential sources of unproductive conflict. Managers of research collaborations therefore have to deal with two categories of differences-integrating diverse relevant contributions and ameliorating problems arising from attributes which are incidental to the partnership.

\subsection{Integrating diverse relevant contributions}

Although effective integration is essential for research collaborations, there is currently no agreed systematic approach to the synthesis of understandings developed in different disciplinary and practice contexts. Consideration of six questions (Bammer and LWA Integration Symposium Participants, 2005; Bammer, 2006a) provides a structured method for describing how integration is achieved:

1. Integration for what and for whom?

2. Integration of what?

3. What was the context in which the integration occurred?

4. Integration by whom?

5. How was the integration undertaken? and

6. Was the integration successful?

\footnotetext{
1 These examples do not include research which has a primary commercialisation focus. Such industry-university research partnerships are widespread and the subject of considerable academic interest. Nevertheless, the issues covered here are relevant to such partnerships. Of course, there are other aspects of such collaborations, such as sharing of risk and financial returns, which are not dealt with in this paper.
}

Each of these questions is discussed in some detail for each of the three case studies. The aim is to demonstrate what a more systematic description of research collaboration would look like and how it would enhance our understanding of integration. Because there is currently no agreed and organized way of describing integration, accounts of it vary greatly in their content and emphasis. This hampers the ability of those involved in research integration to learn from each other and to improve their approaches. Discipline-based research provides a standard to aim for, namely an established way of describing problem framing, key theories and methods. The framework presented here aims to provide a first step for an agreed systematic approach to integration.

\subsubsection{Integration for what and for whom?}

This question makes clear the aims of the collaboration and who is intended to benefit. For the atomic bomb and Human Genome Projects the purposes were concrete, respectively using controlled fission of atomic particles to produce a more powerful weapon and determining the sequence of chemical 'letters' (the bases adenine, guanine, cytosine and thymine) in human DNA. The US government and its World War II allies were the intended beneficiaries of the atomic bomb, whereas the Human Genome Project aimed to provide the international scientific community with a solid foundation from which to tackle the genetic bases of disease (Lambright, 2002; Sulston and Ferry, 2002).

The World Commission on Dams had two objectives: First to "Review the development effectiveness of large dams and assess alternatives for water resources and energy development." And second to "Develop internationally acceptable criteria, guidelines and standards where appropriate, for the planning, design, appraisal, construction, operation, monitoring and decommissioning of dams." (World Commission on Dams, 2000, p. 65). The aim was to set in train a process to achieve "development effectiveness", where "decisionmaking on water and energy management will align itself with the emerging global commitment to sustainable human development and on the equitable distribution of costs and benefits" (World Commission on Dams, 2000, p. xxxiii). Humanity was the intended beneficiary through this commitment.

\subsubsection{Integration of what?}

This addresses the different elements that the collaboration aims to synthesize. At one level this involves the insights of different disciplines and, often also, practitioners. These participants may be located in a number of institutions and, often, a number of countries. Drilling down, this translates into more specific elements for integration-as in epistemological approaches, motivators, visions, values, world-views, geographical- and time-scales and so on. For reasons of space, the case studies are used to highlight the macro rather than the micro levels of differences that these projects aimed to integrate. In each case the collaboration encompassed multiple dimensions.

The atomic bomb project brought together basic science (such as achievement of controlled fission), the solution of a vast range of technical problems (such as developing an implosion trigger device), and engineering and manufacturing prowess (as in generating adequate amounts of 
fissionable material) (Rhodes, 1986). Work was undertaken at three major sites - Los Alamos, Hanford and Oak Ridge - plus a number of other venues across the USA (Groueff, 1967 ) and it is estimated that the project involved 15,000 researchers and more than half a million other workers (Compton, 1956).

In the Human Genome Project, the genome was being worked on in sections, so that the synthesis required assembling and ordering data from the analysed segments. This had to occur both in individual laboratories and across the 20 centres in six countries involved in the project (Collins et al., 2003; Sulston and Ferry, 2002). While this seems relatively simple, to get to that stage significant advances were required in many areas-“increases in automation, sophisticated base-calling software, sequencing assemblers, laboratory management systems, and more advanced sequencing instruments" (Collins et al., 2003, p. 287) and this project also involved "thousands" of researchers (Lambright, 2002, p. 10). In addition, 3\% (later $5 \%$ ) of the budget was allocated to social, ethical and legal research, which was unprecedented in biological investigations (Lambright, 2002).

The World Commission on Dams addressed its two primary aims together by integrating across a very diverse reach in terms of issues, evidence, countries and participants. The Commission worked on a global level and was aiming to achieve balance between demands for irrigation, electricity, flood control and water supply (the benefits of dams) and debt burden, displacement, impoverishment of people, and disturbance of ecosystems and fishery resources (the costs of dams). To do this it considered a range of technical, social, environmental, financial and economic evidence from case studies, country studies, a survey, technical reports, submissions, and fora. It comprehensively covered stakeholder interests in its research and consultation activities, including "government agencies, project affected people and non-governmental organisations, people's movements, the dam construction industry, the export credit agencies and private investors, and the international development community" (World Commission on Dams, 2000, p. viii).

\subsubsection{The context for integration?}

Context involves the political or other action circumstances which led to the project and which may be influential during its life. The context for initiating the atomic bomb project was a major war, where the German enemy was thought to have a 2-year head start in developing an atomic bomb (Compton, 1956). Long-term military advantage was likely also a consideration (Rhodes, 1986). By the time the first atomic bombs were ready for deployment, the wartime situation had changed considerably, with peace in Europe and the focus on forcing an unconditional Japanese surrender. There was most probably also a political eye to justifying the estimated \$US2 billion cost of the project (Rhodes, 1986), although Compton (1956) had previously argued that this was not a factor.

The Human Genome Project was a product of the "Big Science" thinking that was initiated by the atomic bomb project and nurtured in the US Department of Energy, but it was the first time such thinking had been applied outside the physical sciences (Lambright, 2002). In the early days, the involvement of funders and participants was influenced by the rival forces of considerable opposition to the idea within the biological sciences community, as well as jockeying for leadership (Collins et al., 2003; Lambright, 2002; Sulston and Ferry, 2002). Although it set out to be an international undertaking, with significant involvement from several countries in the early stages (OECD, 1995), ultimately the USA and the United Kingdom (UK) were the major players.

The project was funded from public and philanthropic sources. An early unsuccessful attempt to establish the project as a commercial initiative focused the attention of the principle researchers on keeping the knowledge about the genome in the public domain (Lambright, 2002). The most significant contextual factor for this project arose in 1998 when a new company, Celera Genomics, issued a challenge that the research could be conducted more efficiently and effectively in private hands. This led to an acrimonious battle in which the company pursued its interests publicly and aggressively (Lambright, 2002; Sulston and Ferry, 2002). There is no consensus on how the Celera challenge should be viewed. Some argue that Celera deserves to be considered as a major player because the company initiated a genuine race based on a different sequencing method and that its challenge served to speed up the publicly funded process (Lambright, 2002). Others argue that the challenge was based on media hype, with the underlying science kept secret and unable to be independently evaluated, that it was a distraction and irritation soaking up energy from a project that was well on track and continually evolving to improve efficiency, and that it made little real contribution to the sequencing outcome (Sulston and Ferry, 2002). In any case, the private challenge meant that the project became highly visible, with both business and political attentiveness to the implications of the project for national economic competitiveness as well as for improved health. Further it became a venue for playing out an ideological battle between government and business, namely whether the basic sequencing information should be in the public domain or able to be held in private hands and commercially exploited (Lambright, 2002).

The World Commission on Dams was established against a background of increasing controversy about largescale dams and a worldwide stalemate in the building of dams where opponents were causing delays and therefore huge cost overruns (World Commission on Dams, 2000). There had been a change in the power balance, with those adversely affected by dams gaining influence through the transnational anti-dam movement (Khagram, 2004). This was allied to a shift in perceptions about appropriate governance, with increasing demands that governments consult their citizens before acting on their behalf (World Commission on Dams, 2000).

\subsubsection{Integration by whom?}

This question highlights that, even though integration is central to research partnerships, the process of synthesis need not be collaborative. It can be undertaken by an individual, usually the research leader, or by the whole group or a subgroup. Integration often involves a cascade, with 
synthesis occurring within subprojects and then across subprojects. This aspect of integration is often poorly documented.

In the atomic bomb project the overall leader and the scientific leader (General Leslie Groves and Professor Robert Oppenheimer, respectively) were essentially responsible for the overall synthesis of different elements of bomb production. In the Human Genome Project several threads can be deduced from the available literature. First, integration was enhanced by a new funding strategy based on centres rather than individuals (Lambright, 2002). Second, at the most productive stage of the project there was a weekly conference call between the five main centres "to share technical and experimental advances" (Collins et al., 2003, p. 288). These both meant that to some extent everyone had at least a sense of the big picture that they were working towards. Third, a group of eight scientists accepted "final responsibility for ensuring that each chromosome sequence was completed to the pre-agreed standard" (Collins et al., 2003, p. 288). Arguably they had final responsibility for the integration.

In the World Commission on Dams integration was undertaken by the Secretariat and ratified by the Commissioners (S. Khagram, personal communication, 3 August 2004).

\subsubsection{How was the integration undertaken?}

This is the central question. When integration is aimed at a product, such as the atomic bomb or the base sequence of the human genome, the process is analogous to assembling a jigsaw. When the research collaboration has less concrete aims, such as assisting a better decision-making process, integration becomes more complex. At this stage there is no definitive account of methodologies, although starting points have been identified, including risk-benefit analyses, modelling, and deliberative approaches among stakeholders (Klein, 1990; Rossini and Porter, 1979).

Although the World Commission on Dams did not specify the integrative techniques it employed, it laid out an integrative framework for decision making about future dams and probably used many of these processes in its own work. The framework eschewed a "balance sheet" approach to assessing costs and benefits in favour of multi-criteria analysis. A guiding vision was proposed for the integration, namely a globally accepted framework of norms about human rights, social development and environment, as well as economic co-operation, based on United Nations declarations and principles. The framework also favoured negotiation and consensus based on pre-determined priorities and principles. Certainly the Commission report was a consensus document, supported by all the Commissioners (World Commission on Dams, 2000). The World Commission on Dams demonstrated that, in dealing with power imbalances, consideration of values becomes essential. When power among the collaborators is more even, values are more easily ignored, marginalized or taken for granted.

\subsubsection{Was the integration successful?}

This is a question with multiple dimensions. For projects aiming at a product, at least some aspects of success are relatively easy to define and evaluate, especially in terms of whether the product was achieved on time and on budget. In the case of the atomic bomb project, cost was not an issue, but timing was. The project was successful in delivering the product before the war ended. However, even so, debate about the morality of its use means that evaluating the accomplishment becomes more problematic.

For the Human Genome Project, Collins et al. (2003) present a table of goals and achievements, demonstrating that much more was accomplished than originally planned. They also argued that the highly polished sequence was attained 2 years ahead of schedule. In terms of costs, these were originally projected at $\$ 3$ billion (Collins et al., 2003). Lambright (2002) calculated that the US alone spent more than $\$ 3.3$ billion, but notes that this covered several years of testing and improving techniques, often through gene sequencing of other organisms (Lambright, 2002; Sulston and Ferry, 2002). The project either came in over or considerably under budget depending on whether the developmental costs are included or ignored (Collins et al., 2003; Lambright, 2002). It is worth noting that during the key period for sequencing the human genome (1998-2001), the publicly and privately funded teams are estimated to have spent similar amounts, suggesting that there were no efficiencies from conducting the research in the private sphere (Lambright, 2002). In the US, there were also successful outcomes from the research into legal, ethical and social issues, with training provided for judges on the issues and the passage of genetic non-discrimination bills (Collins et al., 2003). Most significantly, the Human Genome Project has started to deliver on its promise of new insights into disease (e.g. Daiger, 2005).

There are even more complexities in assessing the success of the World Commission on Dams, where the outcomes were less tangible. The Commission saw its work as the first step in a longer-term reconsideration of dams, with the Chair assessing the outcome as follows: "Through this process a shared understanding and truth began to emerge, and with it the thin thread with which to sew the stitches of reconciliation" (World Commission on Dams, 2000, p. iii). The fact that the Commissioners, representing a range of interests, were able to produce a consensus report is a positive outcome, which was followed by another in the rapid establishment of the United Nations Environment Programme Dams and Development project (see www.unep.org/DAMS) and in widespread discussion about the report (World Commission on Dams, 2001 and see www.dams.org/report/reaction/). As yet there has been no evaluation of the impact of the Commission's work on the building of new dams or on the re-evaluation of existing ones, although there is evidence that governments, funders and builders for at least some new dams are ignoring the Commission findings (Giles, 2006). More importantly, it is not clear what a fair expectation of impact is when the goals are political and aim to rectify long-standing inequalities.

The success of the Commission can also be assessed in terms of the research process. There was widespread praise for the Commission's extensive work and for its broadening of considerations deemed to be relevant. There was also criticism centring on inadequate consideration of the benefits of dams, and on the impracticality of its proposed 
ways forward (see http://www.dams.org/report/reaction/). Again this begs the question of what can fairly be expected, keeping in mind resource limitations.

\subsubsection{Summary of integration}

In terms of a chief aim of research collaboration, which is to integrate diverse knowledge, perspectives and skills, a significant challenge for research managers is that there is only a murky appreciation of what synthesis involves and how it can be achieved in different projects (Bammer, 2005). The six questions outlined above provide a standard way of describing and thinking about integration. The examples illustrate the kinds of information these questions elicit on a macro level. For any specific collaborative project much more detailed descriptions would be possible. These help research collaboration leaders and managers, as well as those involved in the collaboration, to think more clearly about what they are trying to achieve and how they are going about it. Furthermore, documentation and sharing of these insights within the research community provides the substrate for learning how to more effectively achieve the core integrative tasks of research collaboration.

\subsection{Ameliorating problems from incidental attributes}

A linked challenge for research managers is that the differences between partners are not confined to those which progress the collaboration. There are also differences in personal attributes, incentives required, conceptualisations of research, working style and other attributes which can lead to unproductive conflict. The task for research managers is not to eliminate disagreements and competition, which can provide a vital stimulus to creativity, but to minimise the tensions and disputes which prevent people from working together constructively. There are two strategies which may be useful here. One is to foster reciprocity. The second is to build on a broad sweep of knowledge about personality differences, conflict resolution, building trust and so on, which has been gained in business, community development and other areas (e.g. Gray, 1989; Hackman, 1990; Mandell, 2001; Winer and Ray, 1994). The main problem here is that this knowledge is not compiled in any single place as a resource for research managers.

\subsubsection{Fostering reciprocity}

This has two aspects. First is the precept that partners treat each other as they wish to be treated. This provides a general foundation for satisfactory working relationships based on trust and respect, as well as laying the way to solving problems through principle-based negotiation which seeks fair solutions. The second aspect is that rewards resulting from the research collaboration are allocated commensurately across the research partners, in proportion to their contributions.

The principle of reciprocity does not exclude competition, which is an important motivator. Within any collaboration, there is likely to be a degree of competition between partners for funding or other resources, for dominance of ideas, and for recognition. The partners are also likely to be competing in spheres outside the particular collaboration, such as funding for other projects. Reciprocity plays out here in the avoidance of duplicity. The challenge is to exploit the benefits of the energy and striving for excellence associated with competition, while maintaining mutual respect and minimising underhand behaviour and animosity.

The Human Genome Project illustrates both types of competition. Friendly but fierce competition between the publicly funded centres sparked productivity and innovation (Collins et al., 2003; Sulston and Ferry, 2002). On the other hand, although attempts were made to form a partnership with the private company, Celera Genomics, the fundamentally different interests of public and private research were a barrier to reciprocity.

\subsubsection{Building on knowledge about managing people}

Only a flavour of potentially useful ways of dealing with problematic differences can be given here. Some simple techniques can be surprisingly effective. Personality assessments (such as the Myers Briggs typology; Myers and Myers, 1993), commonly used in team building, often result in conflict melting away, as participants realise that the annoying behaviours of others are not designed to be provocative but simply reflect different psychological make-up and orientation to the world. Enhanced understanding can also ameliorate conflict arising from differences in cultural norms, mental models (Senge, 1990), emotional intelligence (Goleman, 1995), and team role skills (Belbin, 1993). De Bono's “six thinking hats” (1999) provide a way for teams to systematically explore problems from all angles, circumventing unproductive debates and arguments. Principled negotiation, which focuses on differences in interests, is an effective tool for much dispute resolution. It concentrates on creative problem solving and fair accommodation of diverse interests (Fisher et al., 1991; Gray, 1989; Ury, 1993). Promising tools are also being developed to assess trust (Cummings and Bromiley, 1996; Walker and Smith, 2001). The challenge is to make this information accessible by bringing the best methods together in one place. Ongoing development and evaluation of strategies for helping people work together effectively remains a key research gap.

\subsection{Summary of harnessing differences}

Overall, researchers who are leading and managing collaborations have to deal with two categories of differences. One is to integrate diverse relevant contributions. The second is to pay conscious attention to differences incidental to the partnership to prevent them from interfering with the effectiveness of the collaboration. The aim of this section has been to provide researchers with a systematic way of thinking about the challenges of harnessing differences and perhaps some new insights. Each area is ripe for further development. A standardized approach to describing integration is proposed here to provide the substrate for deepening understanding of integrative concepts and techniques. In addition, developing, employing and evaluating strategies for dealing with unproductive incidental differences is a fertile area for collation of what is known and for further investigation. 


\section{Setting defensible boundaries}

Consideration of how to harness differences raises questions about which differences - in terms of disciplinary and practice perspectives - to include in the research collaboration. How can a research manager tell what all the relevant perspectives are likely to be? Given that no research can be fully comprehensive, how should they decide where the boundaries are set? How can they best cope with the distortions introduced by inevitable limitations, such as a set amount of funding and restricted access to personnel?

These are questions that all collaborative research faces, however explicit attention to boundary setting seems to be uncommon and again there does not seem to be a readily available compilation of concepts and methods for research managers to both draw and build on. The aim here is to highlight some pivotal issues about the complexities of boundary setting and the management of inescapable distortions. Attention is drawn to the literature on scoping and two sets of questions which can assist in the setting of boundaries are presented (Section 3.1). The cases are then used to illustrate the inevitable tension between what a research collaboration might ideally like to undertake and what practicalities, such as funding and the availability of researchers with the necessary skills, allow (Section 3.2). Finally, an important, but often overlooked, aspect of boundary setting in collaborations is to nurture and protect the creative element in research. Focusing on the routine application of technical skills and on tightly defined deliverables can mean that opportunities to take creative risks are eliminated. Another way of putting this is that mining what is known without replenishing the stock of knowledge will limit the ability of research to contribute to problem solving in the long term (Section 3.3).

\subsection{Considerations for setting defensible boundaries}

Two areas of existing research provide useful starting points for thinking about how to set defensible boundaries-scoping and Critical Systems Heuristics. Scoping processes have been developed in the environmental sciences (e.g. Executive Office of the President, Council on Environmental Quality, 1981), and are slowly being adopted elsewhere (Bammer, 2006b). These generally focus on identifying and engaging stakeholders to highlight the array of dimensions the project covers and to determine what the extent of the project should be. Analytical descriptions of scoping processes are still relatively uncommon and most focus on prescriptions for managing participatory processes, especially when there is disagreement between stakeholders. Again a series of questions can provide a useful starting point (Bammer, 2006b):

1. What is known about the problem?

2. What can different interest groups and academic disciplines contribute to addressing this problem?

3. What areas are contentious?

4. What are the big picture issues? In other words, what are the political, social and cultural aspects of the problem?

and
5. Why is this problem on the agenda now?

6. What support and resources are likely to be available for tackling the problem?

7. What parts of the problem are already well covered and where are the areas of greatest need?

8 . Where can the most strategic interventions be made?

The first four questions help identify the dimensions of the problem, while the last four help set priorities.

Ulrich's Critical Systems Heuristics (2005) provides the second useful approach to boundary setting, through another helpful set of questions that can be adapted to thinking about boundaries in research collaborations. There are some overlaps with the questions above, but Ulrich's provide a different focus. They highlight four areas for consideration when setting boundaries:

1. the motivation for the collaboration,

2. the sources of power in the collaboration,

3. the sources of knowledge for the collaboration, and

4. the sources of legitimation for the collaboration.

In thinking about the motivation for the collaboration, key questions for determining the boundaries are: Whose interests ought to be served? What should the consequences of the research be? How should success be measured?

In thinking about sources of power, key questions are: Who ought to be the decision maker, i.e. to be able to change the measures of success? What resources and other conditions of success should the decision maker control? What conditions should the decision maker not have control over?

In terms of sources of knowledge: What should count as relevant knowledge and know-how and what should be its role? Who should be involved? Who or what guarantees that the findings will be implemented?

Finally, in terms of sources of legitimation, key questions for determining the boundaries are: Who should argue the case for those who are affected by the research but who cannot speak for themselves (this can include non-human nature)? How are those who cannot speak for themselves treated in the research? What should the visions of success of those involved and those affected be and how should differing visions be dealt with?

Ulrich suggests that these questions are asked not only in the 'ought' mode, as outlined above, but also in the 'is' mode-so that the current situation regarding the research collaboration can be compared with an ideal (or at least improved) situation.

In essence, defensible boundaries suit the objectives of the project. The two sets of questions presented above allow the objectives to be clarified, as well as who is responsible for achieving them. This overlaps with some of the key issues in integration and can provide a helpful iteration with those issues.

On the basis of these questions, the World Commission on Dams provides an excellent example of many of the aspects of defensible boundary setting. It considerably broadened the range of issues deemed relevant, for example, exploring alternatives to building large dams in 
order to achieve irrigation, electricity, flood control and water supply and including a strong human rights aspect to its development of a framework for future considerations about dam building and decommissioning. Another particular strength was its consideration of both pro- and anti-dam interests. As outlined above, the Commission was remarkable in including a comprehensive range of players in its research and consultation activities (World Commission on Dams, 2000).

A particular strength of the World Commission on Dams was the explicit stance taken on values. Midgley (2000) and others have highlighted that boundary judgements and values are intimately connected. This is also illustrated by the Human Genome Project in the clash of values about whether the information about how the four 'letters' which comprise DNA are sequenced in human chromosomes should be in the public domain or able to be commercialized. In this case each side essentially set the boundaries to exclude the other.

\subsection{Managing inevitable restrictions}

The linked task for research managers in setting defensible boundaries involves balancing what the project is aiming to achieve with inevitable restrictions. The focus here is on the first step of highlighting the range of restrictions that may become important. Cataloguing successful management techniques is a significant task for future research.

Two very common limitations are funding and time, as it is rare for projects to have bottomless money and endless time available. The achievements of the World Commission on Dams are particularly remarkable when the tight 2-year time frame and limited budget (just under \$US10 million) are taken into consideration (Scudder, 2001). Another common limitation is personnel availability. Most research managers will recognise difficulties recruiting team investigators with the right skill set and the right level of seniority, as well as in finding practitioner stakeholders willing to be 'engaged'.

There are also a range of other restrictions which can apply to particular collaborations. High-profile projects can also be subjected to political pressure which can affect the boundaries. One illustration comes from the World Commission on Dams where the non-replacement of Chinese Commissioner Shen Gouyi, after her resignation, meant not only that that country distanced itself from the project, but also that the opportunity to conduct a key study on Chinese government-supported resettlement rehabilitation was lost (Scudder, 2001). Political pressure was also important in the Human Genome Project. The publicly funded researchers were forced to share credit with the private company, Celera Genomics, through direct intervention by the US President (Sulston and Ferry, 2002).

On a different scale, power imbalances between disciplines and practice areas or between individuals can also distort the project boundaries. In the atomic bomb project, for example, the dominance of physical scientists, engineers and the military, plus the context of war, meant that the full range of social and ethical considerations was not seriously brought into play until after the first bombs were deployed (Rhodes, 1986). Power imbalances can result either in exclusion, as the previous example illustrates, or in marginalization, where an issue is partly but not fully embraced. The atomic bomb project also provides an example of marginalization in terms of consideration given to environmental impacts. Despite considerable environmental damage at many sites, the only reported investigation was into concern that plutonium production at Washington State's Hanford site might pollute the Columbia River and affect the salmon catch. Although environmental consciousness at that time was still low, it was felt that the local population would react to an impact on salmon fishing. The fear was that this might make them, and perhaps the whole country, more aware of the atomic bomb project and they might turn against it (Groueff, 1967).

Finally, this last example shows that idiosyncrasies can also play a role. The military leader of the atomic bomb project, General Leslie Groves, was the person who ordered the investigation into Columbia River's salmon catch. As well as the potential political issues, his concern was probably also influenced by his father's tales which had invoked a boyhood fascination with the fish (Groueff, 1967).

\subsection{Nurturing and protecting the creative element in research}

Like Thomas Alva Edison's aphorism on genius, research also "is one per cent inspiration and ninety-nine per cent perspiration". Research requires a high degree of specialised skill - whether it is designing and analysing surveys, culturing cells in the laboratory, building mathematical models, or scrutinising historical text - and the routine application of these skills is the mainstay of research activity. In bringing together diverse players to address complex issues, it can be tempting to concentrate on putting specialised skills to well-defined uses and to tightly schedule outputs. Yet, the creative spark requires opportunities to take risks and, often, to learn from failure. Put another way, a major thrust of collaborative research is often to apply what is known rather than to generate new understandings. It can be more challenging and time-consuming to set boundaries so that new knowledge is produced and that this is defensible.

The Human Genome Project struggled most with this tension as its foundation was a highly mechanical activity. Nonetheless, there were "truly exciting scientific challenges" inherent in "the very scale of the problem, along with the need to develop new technologies, new approaches to automation, and new computational strategies" (Collins et al., 2003, p. 286). Starting the identification of gene combinations potentially involved in disease (Sulston and Ferry, 2002) most probably also maintained innovation.

\subsection{Summary of setting defensible boundaries}

In terms of setting defensible boundaries, therefore, research collaborations could be assisted by the compilation of tools that help research managers think about the overall scope of the project, and by critical analysis of how well these tools work in practice. It may also 
be useful for researchers, especially those new to managing collaborations, to have a better understanding of inevitable restrictions, which in turn may lead to more systematic sharing of strategies for coping with them. Further, the particular case of balancing the conflicting requirements of specified outcomes and creativity is a central challenge for research managers and policy makers, requiring additional attention in large-scale complex projects. Research into all these issues would be both timely and apposite.

\section{Gaining legitimate authorization}

Attention to boundaries, and especially the inclusion of powerful stakeholders in research, in turn leads to considerations of legitimacy and authorization. Another impetus is increasingly diversified sources of research funding. Previously, peer-review was the primary authorization mechanism, endorsing the investigation and the collaborations encompassed. However, the vast resources and extent of collaborations involved in mega-projects have always required additional sanction and make the need for external legitimation plain. Further they demonstrate that authorization comes at a cost, with at least some restriction on research independence. They highlight issues that are becoming increasingly common in traditional research, where such restrictions were generally relatively minor, usually shaping an investigation to meet funding priorities. Today's diverse research funding base, particularly the prominence of commercial interests and government demands for research relevance, increasingly challenges research independence. Another important issue for research collaboration leaders and managers is, therefore, working out what level of authorization is needed, how to procure it, and how to minimise the strings attached. Thinking about this challenge is less advanced than about the first two challenges, hence the focus here is on what can be learnt from the case studies.

The three cases illustrate different authorization dilemmas. The atomic bomb project is an example of a straight-forward trade-off, gaining high-level authorization, from the US President, in exchange for military control and extensive secrecy. The Human Genome Project shows what happens when opposing research groups, in this case in the public and private sectors, use conflicting authorizations. A side story in the Human Genome Project is also instructive. The attempt to establish an overarching international Human Genome Organization (HUGO) demonstrates failed authorization. Both the atomic bomb and the Human Genome projects were research-led, with the research community taking the lead in seeking authorization. They were both scientifically 'ripe' for advancement because the underpinning knowledge had advanced to a stage where the scientists saw these mega-projects as a feasible next step. The World Commission on Dams illustrates a different and more complex authorization process, where researchers were only minority players, although they were significant in undertaking the work of the Commission. There is also less information about the trade-offs although there are clear areas for further investigation.

\subsection{The atomic bomb project: trading independence for authorization}

In building the atomic bomb, the focus was on gaining authorization from the US President. This was a protracted process, largely involving influential scientists, who, individually and collectively, lobbied and worked through the National Academy of Sciences and key committees (Compton, 1956; Rhodes, 1986). The President had legitimacy because of his elected status, official power, funding clout and ultimate control of the military. At the time when authorization was sought (1939-1941), the US was not involved in World War II and sentiment against joining the war was strong. Seeking popular or Congressional support would therefore have been futile. There were several other reasons for seeking Presidential-level authorization, including the likely cost of the project, the daring of the idea and the potential military, social and economic applications.

Research independence was curbed by the imposition of military control on the project. There were ongoing tensions between scientific and military ways of operating which the military and scientific leaders had to manage. For example, a balance had to be attained between the need for secrecy and the scientific exchange of information. Further, at Los Alamos Professor Oppenheimer had to fight off attempts to force the scientists to become commissioned officers, and the scientists and their families had to adapt to living behind barbed wire, even though this reminded some of the European émigrés of concentration camps (Rhodes, 1986). There are also tantalizing suggestions that the research was significantly shaped by these arrangements. For example, Groueff (1967, p. 181) states "purely academic scientists were given fantastic amounts of money for their laboratories, unlimited supplies of material and personnel, then were told to succeed at any cost. ... Negative results were not acceptable; even when they offered great theoretical value, they could not be taken into consideration." But no examples are given. Further, Rhodes (1986) argues that, once the atomic bomb project was agreed to, scientists were denied any power in the project and could only choose whether they helped build it or not. This became evident when the commercial company, (then) EI du Pont de Nemours was enlisted to produce plutonium in commercial quantities. This led to "near rebellion" among the scientists who had expected the "right" to keep the project under their own direction until they could "present it to the world as a completed achievement" (Compton, 1956, p. 109). Finally, it is not surprising that the deployment of the uranium- and plutonium-fuelled bombs and the exploitation of the political advantage were not in the scientists' hands. However, in some contradiction to Rhodes' argument, the opinions of key scientists were sought. They concurred with the bombing, especially as they had not been able to convince themselves that any alternative would demonstrate the power of the new weapon, and as polling of a broader group of scientists in-the-know supported military use (Compton, 1956; Rhodes, 1986). 


\subsection{The Human Genome Project: competing authorizations (and failed authorization)}

The Big Science thinking that underpinned the Human Genome Project required funding on a scale previously unheard of in the biological sciences and far above that which could be delivered in the routine governmentsponsored grant allocation process (Lambright, 2002; Sulston and Ferry, 2002). There were two potential sources for such funding-the public and private sectors. While the Human Genome Project refers to the publicly funded project which gained the early momentum, the private sector was a major competing player, especially in the authorization stakes.

In the public sector, the main authorization sought was to make genome research a priority area in the government-sponsored grant allocation process and to attract additional budgetary allocations (i.e. new money) which could be disbursed, often through very large grants. Most of the information about this is available for the US and the UK (Collins et al., 2003; Lambright, 2002; Sulston and Ferry, 2002), but an Organization for Economic Cooperation and Development report (OECD, 1995) shows that similar considerations also applied in other jurisdictions, including Canada, the European Union as a whole and France individually (France also had private sector interest), Japan, and Russia. (The countries that finally made a contribution were China, France, Germany and Japan (Collins et al., 2003).)

In the US, a special committee of the National Research Council of the National Academy of Sciences played a key role through its 1988 report, which called for a 15year project with funding of around $\$ 200$ million per year (Collins et al., 2003; Lambright, 2002). Congressional support made this funding available through the National Institutes of Health, which took over as lead funder from the Department of Energy, the original sponsor of the Big Science approach (Lambright, 2002). In the UK, the government made new funding available to the Medical Research Council to launch the UK Human Genome Mapping Project. The UK-based philanthropy organization, the Wellcome Trust, also became a major player when its funding base doubled in 1992 and it was persuaded to spend a significant proportion of this additional money on supporting the Human Genome Project. It subsequently became the major UK contributor, and by funding the sequencing of one-third of the human genome, made the UK a major player internationally (Sulston and Ferry, 2002).

The main private sector players were also in the US. Influential researchers first sought commercialization partners in 1987, but were unsuccessful (Lambright, 2002; Sulston and Ferry, 2002). Private sector interest then coalesced around the scientific leadership of Dr. Craig Venter, who had previously worked at the National Institutes of Health. In 1998 he became scientific director of the newly established company Celera Genomics. Republican Party control of the US Congress (after 1994) provided high-level support for replacing the publicly funded effort with a privately funded one, thus the authorization for the project started to change away from government support for a public project to benefit all of humankind to government support for private enterprise and commercialization of the basic sequencing information. Celera's case was further helped because Craig Venter was "an old friend" of (Democratic) President Bill Clinton (Clinton, 2004, p. 910). Significantly, although President Clinton and UK Prime Minister Tony Blair eventually came out in support of the sequence information being in the public domain (Collins et al., 2003; Lambright, 2002), it was also President Clinton who intervened in the acrimonious battle to push for credit sharing on an equal basis between the public and private sector researchers (Clinton, 2004; Sulston and Ferry, 2002).

The key players at the US National Institutes of Health, the US Department of Energy and the UK's Wellcome Trust subsequently alluded to the challenging nature of "the art of keeping a long-term scientific project - and its budget - on course in an ever-changing sea of political masters with many different agendas" (Collins et al., 2003, p. 288). The substantial funding provided by the UK's Wellcome Trust was thought to have significantly fortified the National Institutes of Health's ability to resist a private take-over (Sulston and Ferry, 2002).

Apart from the political backing for different values and players, there were also other factors that were influential in deciding the outcome between the competing authorizations. Before 1998, very little effort had actually gone into sequencing human DNA, with most of the money being spent on methods to make the sequencing faster and cheaper. On one hand, this fuelled the private sector claim that it could be more efficient and effective. Indeed Dr. Venter's impatience with the strategy and inability to attract National Institutes of Health funding for his own methods, influenced his decision to seek private backing (Lambright, 2002). Some researchers in the publicly funded group also wanted to move faster on sequencing, but were committed to the public domain research and so worked within its confines (Sulston and Ferry, 2002). On the other hand, the long-term strategy was in line with the original recommendations of the National Research Council and well laid out with an interim goal and deliverables, so that achievements could be demonstrated. Lambright (2002, p. 30) suggested that:

Had the interim goal not been set and achieved, that support might well have eroded. Goals, organization, and political support go together in government programs, one influencing the other. Politicians may understand little about the technical details of HGP [Human Genome Program], but they do think they know something about schedules and money. They react negatively to what they perceive as mismanagement, as seen in schedule slippage and cost overruns. Hence, what HGP had to do was to show results to keep the confidence of elected officials.

In the Human Genome Project, the Big Science funding requirements meant that the whole way that research was organized changed. Despite clearly stated opposition in the 1988 National Research Council report to allowing a small number of centres to dominate the sequencing effort, that was the outcome. The successful centres operated in an industrial fashion (Lambright, 2002; Sulston and 
Ferry, 2002). Others had their funding phased out, especially "centers that were failing to reach the most ambitious levels of production and cost efficiency. Just meeting goals was not enough; the centers that succeeded were those that constantly innovated and stretched beyond original expectations" (Collins et al., 2003, p. 287). This trend was given impetus by the private sector challenge (Lambright, 2002). Although this had impacts on research independence, their benefits and costs do not seem to have been evaluated.

\subsubsection{Failed authorization}

Finally, the Human Genome Project also illustrates that research managers and policy makers are not always successful in gaining authorization. HUGO, the Human Genome Organization, was to be the international coordinating mechanism but, despite elite membership and high-profile leaders, was never able to attract enough funding to establish its position (Anderson and Aldous, 1992). In the end, the coordination was led by the National Human Genome Research Institute at the US National Institutes of Health (Lambright, 2002; Sulston and Ferry, 2002).

\subsection{The World Commission on Dams: complex authorization with hidden trade-offs}

The World Commission on Dams demonstrates a different authorization process. A 1997 workshop hosted by the World Conservation Union and the World Bank brought together 35 representatives of pro- and anti-dam interests, which unanimously recommended the establishment of the Commission (IUCN-World Conservation Union and the World Bank Group, 1997; Scudder, 2001; World Commission on Dams, 2000). Legitimacy was based on both power and moral authority. The former came through the standing of the World Conservation Union and the World Bank. The latter derived from the balance of interests represented by influential players on both sides of the dams debate. The Commission systematically built up its moral legitimacy by striving for balance among its 12 commissioners and its 68 member stakeholder forum, as well as its broad funding base drawing on 53 public, private and civil society organizations (World Commission on Dams, 2000). The status of research also contributed to the legitimacy of the Commission. Research was seen as the solution to a political problem, which had become pressing because of the growth and increasing power of the transnational anti-dam movement (Khagram, 2004).

In the case of the Commission, the costs of the authorization process cannot be readily discerned, as there are few insider reflections or analyses of the process. Questions for investigation include: Did getting everyone to the table preclude a more action-oriented agenda, leading to focus on a framework for action, rather than action itself? Did the resignation of the Chinese Commissioner make it easier for the Commission to reach agreement, but pave the way for China to circumvent the Commission's findings by providing funding for new dams but ignoring the Commission's framework (Giles, 2006)?

\subsection{Summary of gaining legitimate authorization}

As research has become more large-scale and directly engaged with real-world problems, as the diversity of funding sources has grown, and as governments, private industry, community groups and others have become more proactively involved in research, research managers are needing to pay more specific attention to authorization issues. At this stage there is little to guide these considerations, apart from the lessons which can be drawn from case studies, such as those described above. This is another area for fruitful investigation.

\section{What does all this mean for evaluating research collaborations?}

One benefit of thinking more systematically about research collaborations is that the insights gained can be useful for evaluation. The topics discussed earlier harnessing differences, setting defensible boundaries and gaining legitimate authorization - provide some additional considerations for research design, methods, results and conclusions.

In terms of research design, evaluators could ask: How defensible are the boundaries of the collaboration? Were all the necessary actors and considerations included? Were limitations dealt with effectively? Was the normative base sound?

In terms of methods, key questions include: Were effective integrative methods used? Would other methods have made useful contributions? Were incidental differences managed effectively or did they get in the way of producing successful outcomes? Were the collaborators treated fairly in terms of meeting their interests in the collaboration and in the distribution of the rewards of the collaboration?

For results: How well did the collaboration meet its aims? Was effective integration achieved? Were influential new insights produced? Did effective action result?

And, finally, in terms of conclusions: Can the claims made by the researchers be substantiated? Has research independence been compromised?

These questions cover the considerations used to evaluate any research, as well as additional elements introduced by collaboration and integration. The former address the more general issues of: Did the research do what it set out to do? Was the problem definition appropriate? Were the best methods used? Were appropriate conclusions drawn? The latter highlight unique dimensions of collaborative research, which also warrant evaluation. First is the emphasis on good collaborative practice. It is useful to think of the questions on fair treatment of partners and management of incidental differences as analogous to good laboratory management in traditional scientific endeavours. It is now taken for granted that experimental results cannot be trusted unless the conditions are uncontaminated, equipment is in good working order, measuring instruments are accurate, and staff are appropriately trained. The point of the analogy is that good collaborative process requires the same matter-of-fact consideration and suitable allocation of resources. There seems to be little available knowledge, 
however, about what resource allocation is reasonable for collaboration.

The second issue specific to collaborative research is how best to evaluate claims for partnership success. While it can be tempting to develop complex evaluation approaches, a simpler approach is to enlarge peer-review by developing a new college of peers-those who have themselves led collaborative projects of the type being assessed (e.g. involving researchers only, involving researchers and practitioners of relatively equal standing, or involving researchers and practitioners with very different power). However, to conduct their assessment, these peers will require key elements of collaboration and integration to be described in ways that are not standard now, but which are outlined in this paper. This would allow peer-reviewers to effectively assess the integration methods, boundary setting and authorization, as well as how the inevitable trade-offs had been met.

\section{Conclusions}

As researchers are increasingly called on by governments, business, the representatives of powerless community groups and others to assist with tackling the complex problems societies face, collaborations are growing in importance. This paper provides a number of ideas to stimulate exploration of key elements of partnerships that are likely to influence collaboration success. I conclude by highlighting where further compilation of evidence or new investigations may be useful in expanding the ideas presented here:

- applying and further developing an agreed framework to systematically describe the integration of the various perspectives and elements fundamental to harnessing difference in any particular collaboration;

- making a compendium of methods for managing personality, value, world-view, research approach and other differences which are incidental to, but have the potential to significantly disrupt, partnerships and which can be used to foster reciprocity;

- building on scoping and Critical Systems Heuristics to develop systematic ways of defining the boundaries of research collaborations;

- learning from diverse partnerships about how inevitable pressures which constrain the boundaries - like limited funding, time and other resources, political pressure, and power differences between disciplines - can best be recognised and accommodated, as well as how creativity can be nurtured in a 'deliverables' culture;

- researching diverse partnerships to better understand processes of authorization, trade-offs and preventing restrictions on research independence; and

- expanding evaluation criteria and processes so that research collaborations can be adequately assessed and an increasing body of experience and knowledge can be built.

\section{Acknowledgements}

The Fulbright New Century Scholars Program and the Colonial Foundation Trust, through the Drug Policy Mod- elling Program, supported this research. Useful suggestions were received from Warren Bond, Dorothy Broom, L. David Brown, Bill Clark, Nancy Dickson, Jane Dixon, Sanjeev Khagram, Mark Moore, Alison Ritter, Lorrae van Kerkhoff, Yoland Wadsworth and two anonymous reviewers. Caryn Anderson assisted with the references.

\section{References}

Adams, J.D., Black, G.C., Clemmonsc, J.R., Stephan, P.E., 2005. Scientific teams and institutional collaborations: evidence from U.S. universities, 1981-1999. Research Policy 34, 259-285.

Anderson, C., Aldous, P., 1992. Still room for HUGO? Nature 355, 4-5.

Bammer, G., 2005. Integration and implementation sciences: building a new specialization. Ecology and Society 10(2), 6 [online] URL: http://www.ecologyandsociety.org/vol10/iss2/art6/.

Bammer, G., 2006a. A systematic approach to integration in research. Integration Insights \#1, September. Available at www.anu.edu.au/iisn.

Bammer, G., 2006b. Scoping public health problems. In: Pencheon, D., Guest, C., Melzer, D., Gray, J.A.M. (Eds.), Oxford Handbook of Public Health Practice, second edition. Oxford University Press, Oxford, pp. 4-11.

Bammer, G., LWA Integration Symposium Participants, 2005. Guiding principles for integration in natural resource management (NRM) as a contribution to sustainability. Australasian Journal of Environmental Management 12 Supplement, 5-7.

Belbin, M., 1993. Team Roles at Work. Butterworth-Heinemann, Oxford.

Bozeman, B., Corley, E., 2004. Scientists' collaboration strategies: implications for scientific and technical human capital. Research Policy 33, 599-616.

Chompalov, I., Genuth, J., Shrum, W., 2002. The organization of scientific collaborations. Research Policy 31, 749-767.

Clinton, B., 2004. My Life. Alfred A. Knopf, New York.

Collins, F.S., Morgan, M., Patrinos, A., 2003. The Human Genome Project: lessons from large-scale biology. Science 300, 286-290.

Compton, A.H., 1956. Atomic Quest. A Personal Narrative. Oxford University Press, London.

Corley, E.A., Boardman, P.C., Bozeman, B., 2006. Design and the management of multi-institutional research collaborations: theoretical implications from two case studies. Research Policy 35, 975-993.

Cummings, L.L., Bromiley, P., 1996. The organizational trust inventory. In: Kramer, R.M., Tyler, T.R. (Eds.), Trust in Organizations. Frontiers of Theory and Research. Sage, Thousand Oaks, CA, pp. 302-330.

Daiger, S.P., 2005. Was the Human Genome Project worth the effort? Science 308, 362-364.

De Bono, E., 1999. Six Thinking Hats. Back Bay Books, Little, Brown and Company, New York.

Executive Office of the President, Council on Environmental Quality, 1981. Memorandum for General Counsels, NEPA Liaisons and Participants in Scoping. April 30, 1981. http://ceq.eh.doe. gov/nepa/regs/scope/scoping.htm.

Fisher, R., Ury, W., Patton, B., 1991. Getting to Yes. Negotiating an Agreement without Giving In. Random House Business Books, London.

Giles, J., 2006. Tide of censure for African dams. Nature 440, 393-394.

Goleman, D., 1995. Emotional Intelligence. Bantam, New York.

Gray, B., 1989. Collaboration: Finding Common Ground for Multiparty Problems. Jossey-Bass, San Francisco.

Groueff, S., 1967. Manhattan Project. The Untold Story of the Making of the Atomic Bomb. Little, Brown and Company, Boston.

Hackett, E.J., Conz, D., Parker, J., Bashford, J., DeLay, S., 2004. Tokamaks and turbulence: research ensembles, policy and technoscientific work. Research Policy 33, 747-767.

Hackman, J.R., 1990. Groups that Work (and Those that Don't). Creating Conditions for Effective Teamwork. Jossey-Bass, San Francisco.

IUCN-World Conservation Union, the World Bank Group, 1997. Large Dams: Learning from the Past, Looking at the Future. Workshop Proceedings. IUCN-World Conservation Union, Gland, Switzerland and World Bank Group, Washington, DC. http://www.dams.org/docs/largedams.pdf.

Katz, J.S., Martin, B.R., 1997. What is research collaboration? Research Policy $26,1-18$.

Khagram, S., 2004. Dams and Development. Transnational Struggles for Water and Power. Cornell University Press, Ithaca.

Klein, J.T., 1990. Interdisciplinarity: History, Theory and Practice. Wayne State University Press, Detroit.

Lambright, W.H., 2002. Managing "big science": a case study of the Human Genome Project. New Ways to Manage Series. The Price- 
waterhouseCoopers Endowment for the Business of Government. http://www.businessofgovernment.org/pdfs/LambrightReport2.pdf.

Landry, R., Amara, N., 1998. The impact of transaction costs on the institutional structuration of collaborative academic research. Research Policy 27, 901-913.

Lee, Y.S., 1996. 'Technology transfer' and the research university: a search for the boundaries of university-industry collaboration. Research Policy $25,843-863$.

Mandell, M.P.(Ed.), 2001. Getting Results through Collaboration. Networks and Network Structures for Public Policy and Management. Quorum Books, Westport, Connecticut.

Melin, G., 2000. Pragmatism and self-organization. Research collaboration on the individual level. Research Policy 29, 31-40.

Midgley, G., 2000. Systemic Intervention: Philosophy, Methodology, and Practice. Kluwer Academic/Plenum Publishers, New York.

Myers, I.B., Myers, P.B., 1993. Gifts Differing. Understanding Personality Type. CPP Books, Palo Alto, CA.

OECD, 1995. The Global Human Genome Project. Megascience: The OECD Forum. Organisation for Economic Co-operation and Development, Paris.

Porac, J.F., Wade, J.B., Fischer, H.M., Brown, J., Kanfer, A., Bowker, G., 2004. Human capital heterogeneity, collaborative relationships, and publication patterns in a multidisciplinary scientific alliance: a comparative case study of two scientific teams. Research Policy 33, 661-678.

Rhodes, R., 1986. The Making of the Atomic Bomb. Simon and Schuster, London.

Rigby, J., Edler, J., 2005. Peering inside research networks: some observations on the effect of the intensity of collaboration on the variability of research quality. Research Policy 34, 784-794.
Rossini, F.A., Porter, A.L., 1979. Frameworks for integrating interdisciplinary research. Research Policy 8, 70-79.

Scudder, T., 2001. The World Commission on Dams and the need for a new development paradigm. Water Resources Development 17, 329341.

Senge, P.M., 1990. The Fifth Discipline. The Art and Practice of the Learning Organisation. Century Business, Imprint of Random House UK, London.

Sulston, J., Ferry, G., 2002. The Common Thread. A Story of Science, Politics, Ethics and the Human Genome. Bantam Press, London.

Ulrich, W., 2005. A brief introduction to Critical Systems Heuristics (CSH). Available at http://www.geocities.com/csh_home/downloads/ ulrich_2005f.pdf.

Ury, W., 1993. Getting Past No. Negotiating your Way from Confrontation to Cooperation. Bantam Books, New York.

Wagner, C.S., Leydesdorff, L., 2005. Network structure, self-organization, and the growth of international collaboration in science. Research Policy 34, 1608-1618.

Walker, R., Smith, P., 2001. Evaluating trust in collaborative relationships. Paper presented at Health Services and Policy Research Conference, Wellington, New Zealand, December.

Winer, M., Ray, K., 1994. Collaboration Handbook. Creating, Sustaining and Enjoying the Journey. Amherst H. Wilder Foundation, Saint Paul, MN.

World Commission on Dams, 2000. Dams and Development: A New Framework for Decision-Making. Earthscan, London. http://www.dams.org//docs/report/wcdreport.pdf.

World Commission on Dams, 2001. Final WCD Forum. Report, Responses, Discussions and Outcome. World Commission on Dams, Cape Town. http://www.dams.org/commission/forum/forum_3.htm. 